interest in case the observations in England are not in conformity with those of mine. In case the observations in England happen to conform we shall have to find reasons for the statements in the text-books.

Yours truly,

Ram Kishan Handa.

Massy Gate, Rawalpindi.

January 19, 1940.

\title{
OBITUARY
}

\section{R. J. LYTHGOE}

The untimely death of R. J. Lythgoe is a tragedy not only to his relations and friends, but also to science. The experimental study of the special senses has been grievously neglected in England both by physiologists and psychologists. Until comparatively recently our knowledge of visual phenomena under different conditions of illumination, etc., was advanced mostly by physicists, generally inspired by practical problems of artificial lighting, and often vitiated by ignorance of the extremely complicated anatomical and physiological facts which determine the neural and psychological responses. Lythgoe took up these problems at the outset of his work as a Beit Research Fellow. That he was able to devote himself un remittingly to them to the end of his life is due to the encouragement he received from the Medical Research Council, and the permanency of tenure of his post under their aegis. His paper on "The adaptation of the eye: its relation to the critical frequency of flicker" in 1929, embodying the results of experiments conducted with the help of his future wife, Miss K. Tansley, revealed new facts in a domain already thoroughly exploited by physicists-facts heartily accepted by them owing to the care and accuracy of his physical measurements. The same accuracy and originality were displayed in his paper on "The measurement of visual acuity," also published in the Special Report Series of the Medical Research Council, in 1932. Both these papers mark new stages in the history of the scientific investigation of visual capacity. During the last few years Lythgoe has been engaged in collaboration with Goodeve and others in an exhaustive investigation of the physical and chemical properties of visual purple and its decomposition products under the influence of light. These researches have been published in the Proceedings of the Royal Society and the Journal of Physiology. They too reveal a stride forward in our knowledge. 
Whilst those who knew him personally mourn the loss of a lovable, modest and retiring searcher after truth, science loses an original thinker and expert craftsman who, had he lived longer, would have stimulated others to follow in his footsteps. More truly than in most cases it may be said that he is irreplaceable.

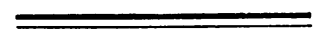

\section{NOTES}

Death

THE death is announced on November 13, 1939, of Professor Anton Elschnig, at the age of 76 years. Most of his professional career was spent in Prague, where he was Professor of Ophthalmology and his reputation in ophthalmology was international. There is an obituary notice of him by one of his old pupils, Karl W. Ascher, in the American Journal of Ophthalmology, February, 1940, to which we are indebted for this information.

Ophthalmological Society of Egypt
THE Annual Congress of the Ophthalmological Society of Egypt took place at the Memorial Ophthalmic Laboratory, Giza, on March 29-30, 1940. The discussion was on blepharitis. The notice reached us too late for insertion in the March number.

\section{FUTURE ARRANGEMENTS}

April 25-26, 1940. - Ophthalmological Society of the United Kingdom. Annual Congress.

May 4, 1940.- North of England Ophthalmological Society, at Newcastle-on-Tyne.

July 4-6, 1940.-Ophthalmological Congress, at Oxford. 